\title{
The Application of AR Technology to Spatial Skills Learning in Carpentry Training
}

\author{
I-Jui Lee, Ting-Chun Hsu, Ten-Li Chen, and Meng-Cong Zheng
}

\begin{abstract}
Furniture carpentry requires plentiful cognitive judgements of views and capability of spatial understanding. For beginners, the idea of spatial geometry in mortice-tenon structure is often hard to comprehend, and being restricted by traditional 2D graphic, lacking basic 3D spatial concept. Yet augmented reality (AR) has already been proven to be capable of geometry training and enhancing conceptual manifestations of 3D space. Through combination of solid controller and virtual 3D subject of AR, dual feedbacks in both senses of touch and vision, this study aims at enhancing beginners' spatial skills in the making of furniture carpentry and further the improvement of carpentry skills. After experiments of each phase, evaluations are done through questionnaires and experts' observations on furniture works. It has proven that AR technique can truly and efficiently solve the perspective problems in complicated and implicit structure and spatial obstacles in furniture carpentry learning for beginners.
\end{abstract}

Index Terms-Augmented reality, carpentry, geometry learning, implicit structure, spatial skills.

\section{INTRODUCTION}

The basic furniture carpentry learning ranges from spatial and structure viewing judgements, materials selection, spare parts fabrication, assembling, coating and polishing, etc. [1]. For beginners, the preliminary difficulty is $2 \mathrm{D}$ view judgements of furniture, lacking spatial senses of 3D subject and experience of mortice-tenon fabrication. It is difficult for 2D views' judgement in furniture making [2], finally influencing materials cutting and making errors in fabrication and assembling of mortice structures. Spatial views judgement is the primary technique for furniture fabrication learning in the course of furniture carpentry [2]. Views judging and cutting of each timber component and laying of mortice-tenon structures are the first step to furniture fabrication learning, and it is necessarily to be applied in spatial structure and mental ability in geometry recognition. Yet in the making of furniture, 3D spatial views judgement and furniture making has a significant correlation with spatial ability [3], for it is required in furniture maker to translate 2D drawing into 3D vertical views through spatial ability [2]. However, in training of traditional furniture carpentry, learning spatial geometry usually demands students to generate and manipulate 3D mental images from 2D objects, and it may cause cognitive overload [4] and learning difficulties for some students [5]. In previous literature work

Manuscript received June 11, 2018; revised August 3, 2018.

The authors are with the National Taipei University of Technology, Taipei, Taiwan (Corresponding Author: I-Jui Lee and Ting-Chun Hsu; e-mail: ericlee@ntut.edu.tw, hsu1030@gmail.com, chentl@ntut.edu.tw, zmcdesign@gmail.com). we found, in 3D space, starter learners have little experience in operation of subject and visual feedback; inhibit them from understanding fabrication of furniture structure (a 3D subject) from spatial views of 2D [6], and the difficulties in learning furniture carpentry views. Besides, there are still a lot of hidden problems in spatial views and mortice-tenon skills in the basics of carpentry views, only by training views' judgement on a 2D basis, it is still quite difficult for beginners, because beginners are incapable of picturing potential view problems [6] such as, 3D section of a dovetail mortice, or assembling of Luban tenon. So, it is often the case that beginners miss-cut the useful sections in the making of parts of mortice-tenon structure, or the elimination of ready fabricated parts due to misjudgments, causing the failing of assembling holes and shortage on materials. Hence, it is very critical to develop efficient skills and strategies of spatial knowledge required in furniture carpentry.

\section{RELATED WORKS}

\section{A. Importance of Spatial Skills}

For beginners in furniture carpentry, it usually begins with interpretation and judgements of furniture 2D spatial views. The assembling structure of furniture is learned from different perspectives; in this professional world, spatial visualization skills and mental rotation capabilities are important for technical professions such as furniture maker, draftsman, etc. [7]. In the previous study on spatial skills training, Uttal et al. (2013) found that spatial skills were "moderately malleable and that training, on average, improved performance by almost half a standard deviation" [8]. This evidence also helps explain why well-experienced hand in furniture carpentry has obvious advantages in judgements and keenness of spatial views compared with beginners [9], in a result which is by long-term accumulation of experience in practice [6], [10], therefore, it has been proved that the promotion in judgements of spatial awareness is of tremendous help to furniture design and fabrication [2].

\section{B. AR Technology in the Developing of Spatial Ability}

The technique of $\mathrm{AR}$ makes the learning of spatial geometry idea easier, enabling the manipulation of virtual object through 3D control subject and the understanding of spatial structure, a way really by instincts; that is with concrete learning material and hands-on activities [11]-[13]. It has been put forward in past literatures that it is trainable for spatial ability and that AR technology is applicable in training and judgement of geometry and spatial awareness [14]. Related research has been done in 3-view courses with AR technology among undergraduates and has been proved the 
assistance to views judgement from training on AR [15]. Besides, it has also been found in related research that AR technology has the ability of promoting learners' interests and motives [16], increasing understanding in spatial concept and meanwhile reducing recognition load of spatial awareness in learning [14]. In addition, previous studies also conferred on the tremendous potential for using 3D dynamic multimedia such as AR technology in teaching geometry [17]. For instance, Silva \& Silveira (2012) presented ARGeometric [18]; an educational tool in the field of geometry proposes a game development methodology. Others, [15] presents a study that integrates AR technology into teaching activities to design a learning system that assists junior high-school students in learning solid geometry [19]. AR is considered as a better solution to afford spatial ability training, especially for focus on the presentation of 3-D space [20], because it allows students to view the spatial relationship of real world objects that is impossible to be implemented in traditional textbooks. AR also provides students a more intuitive way to manipulate virtual objects. Related studies have shown that this type of manipulation can help mental rotation [14], [21]-[23]. Furthermore, with the advantage of presenting full $3 \mathrm{D}$ holograms, AR technology does not require the user to translate a $2 \mathrm{D}$ image into a $3 \mathrm{D}$ model. $\mathrm{AR}$ can reduce learners' cognitive load and increase their interest in training [24]-[26]. AR interfaces can directly provide real-time 3D visual support with surrounding information and promote spatial visualization [27], [28]. Therefore, in the present study, we use AR to present a complete $3 \mathrm{D}$ animation with real spatial information of the background environment, allowing the user to see the virtual 3D model rotate corresponding to a tangible manual controller (cube) rotating in their hand. Besides the anticipated training of traditional carpentry skills exercises in learning courses, so the user has real motor perception and visual feedback from the 3D spatial visualization display. Teaching assistance from dual-feedbacks of visual and touching senses will be gained through 3D AR technique combining with subject, for the improving of spatial views judgment ability and lowering of learning difficulties in mortice-joining for starter learners of furniture carpentry.

\section{METHODS}

\section{A. Participants}

This research mainly recruited 36 fresh undergraduates at the age among 19-21 (mean age: 19.7 years; $S D=1.38 ; 19$ women; 5 left-handed participants), and are proven to have no related experience in carpentry and views through investigation prior classes. Through pre-testing, their abilities on views judgement are not strong (done through testes of carpentry skills questions, result of which shows medium-low level), causing them facing difficulties in fabricating basic mortice-tenon structure of wooden furniture. So, through pre-testing on abilities of views, 36 students are randomly divided into two groups, experimental and control group, 18 of them undergo an extra training on AR technique, which enables them to understand correlations between $2 \mathrm{D}$ views and mortice of $3 \mathrm{D}$. In the process, it is through group dividing and each group 2 students, with each one accessing the system. This scheme of interruption is undertaken before teaching unit of each stage, with narration of process of operation of $\mathrm{AR}$ and interaction relationships among mortice-tenon structure surfaces. Yet the other group (18 students) undergoes traditional basics learning of carpentry.

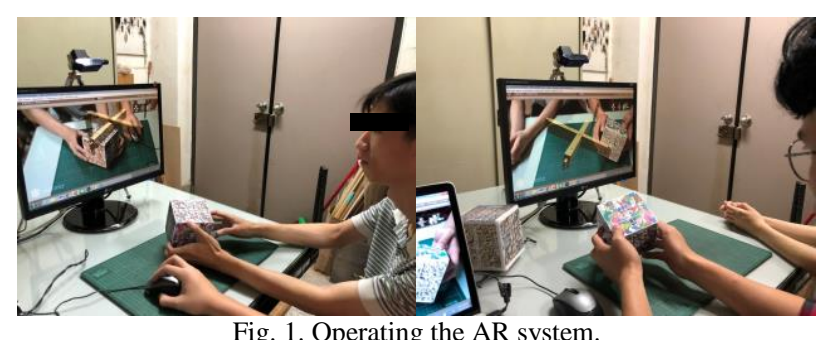

\section{B. Operational Scenario and Facilities}

After completion of preliminary functions, hardware structure for operation of subject is constructed. Most of mortice-joining is vertical mortice-tenon structure composed by 2-3 forming parts, characteristic of which lies in integration of simple geometry structures into an independent and complete piece, being solid both in directional and structural aspect. However, in 2D drawing, it is unable to see the status of its fabrication and assembling. And the manner of hand-held subject demands the functions of hand-held direction and rotating observation and reading of each view. So, in the design of operation object, square object close to outlook of Luban tenon is selected as operation object with similar outlook and shape. Square object has six views; surface of each view being the subject of recognition of AR, augmented 3D motion picture adjusts whirling angles along the hand gesture of operator, presenting effects of perspective and 3D motion picture (Fig.1).
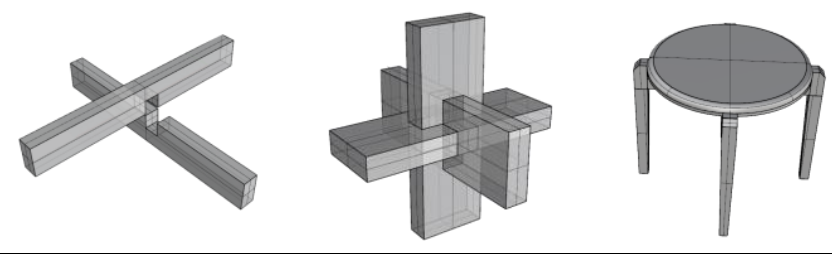

(1) Preliminary: cross (2) Mid-level: Luban overlapping mortises tenon joint

\section{(3) Advanced:} including cross overlapping and mortise-tenon joints

Fig. 2. Three levels of difficulty of mortise-tenon task.

In training materials, instructions are done through researcher and instructor, and cross overlapping tenon is selected as preliminary training material, Luban tenon as mid-level material, the advanced being the fabrication of chair integrated with these two techniques (Fig.2). The views of 2D drawing are all from testing of carpentry skills, and contents of motion picture of 3D are through AR, constructing matching controlling part. Students are acquainted with different mortice-tenon ideas that are to be applied into actual operation of carpentry.

\section{Design}

The goal of this analysis is to strengthen ability in judgements of mortice-tenon in each view of carpentry, 
improving students' understanding in spatial structure of furniture mortice-tenon and geometry ideas and skills through combination of simulated 3D motion picture with physical operation subject. The location of experiment is in interns' workshop class for carpentry in school, and the training scheme is by alternating operation of AR of students, observing 3D subject of drawing through hand-held device. The subject rotates along turning of hand gestures, adjusting spatial positions, switching to (1) perspective image (2) rendering image of materials, (3) three different augmented browsing models of motion picture (Fig.3). Also, learners are able to observe status from different perspectives and views according to controlling subject in hand, increasing spatial cognition and familiarity with carpentry drawing in the meantime. Both students in experimental and control group are able to fulfill training of actual carpentry work of three levels. Hard equipment including 27 inch display, square manual controller, and virtual mortice-tenon objects by AR, video camera, and an i7 laptop. The controller sat in front of screen, observing virtual subject in screen, with controller in his hand labeled with recognizable icons in six surfaces for surveillance of spatial coordinates by video camera, translating into virtual subject by AR technology in screen presentation.
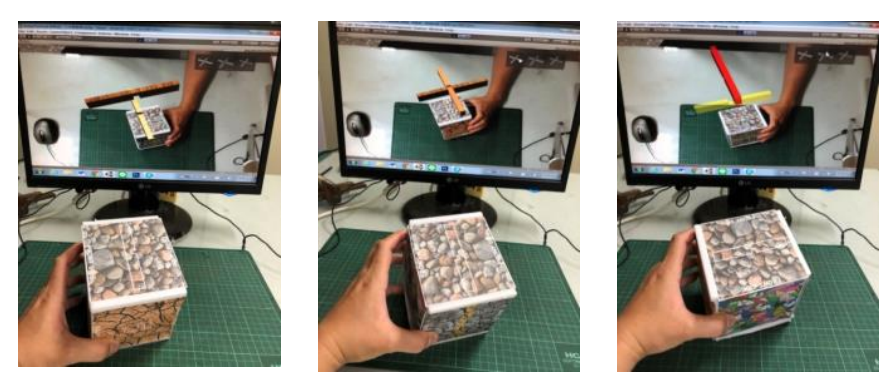

Fig. 3. AR system had three different modes (a. assembly animation mode (left); b. rendering mode (center below); c. transparent mode (right).

\section{Procedure}

This research is divided into 3 training stages, with a new teaching unit of carpentry each 4-6 weeks. According to levels of different training materials (preliminary, mid-level, advanced) training on actual work is taken by students in each level.

\section{Step 1: Stacking of image of 3D AR for judgement of 2D views}

Prior to initiation of training courses in each unit, experimental group will undergo AR operation and teaching, enabling students the understanding of assembling status of subjects for mortice-tenon structure by 2D views judgements, physical console (square shape) and AR 3D stimulus motion picture. Each student is required to operate himself and rotate virtual subject for understanding of structures of different mortice-tenon and spatial geometry status of mortice-tenon. Through model switch of image, perspective status of different subjects and forming stimulus motion picture is observed.

\section{Step 2: Actual carpentry operation}

Upon completion, students initiate the phase of fabrication of forming pieces of carpentry work. In the process, 3D contents observed in AR will be applied, coupling onto actual sawing cutting and assembling of carpentry subjects.

\section{Step 3: Evaluations of subsequent phase}

After actual sawing and cutting and assembling of carpentry work, instructor will access the correctness and completion level of work, evaluations will be done along skills assessment standards in a multi-directional level. The instructor has experience for more than 20 years regarding carpentry and possess license for skills assessments, determining soundness of image performance in fabrication from work fineness, correctness of assembling and angle directions.

\section{E. Data Collection and Analysis}

Data of experimental group take the form of questionnaire and evaluation of instructors. After three stages, a questionnaire will be conducted for survey of satisfactions level and assessments of works. Through contrast of work of experimental and control group (each 18 members), testing which includes correctness, joining accuracy, completion level within time will be conducted for a unified rating of scores. Through pairing sample t-testing with scores of control group, the determination of whether the application of AR in experimental group with physical operating object has improved skills in learning.

\section{Results}

The results of our four-month experiment revealed that AR technology has the effects on the experimental group with satisfactory results. All participants in the experimental group agreed that the AR had a positive training effect in that the novelty of the 3-D presentation of AR helped them to understand the 2-D view of the mortise-tenon joint (average level of agreement $=4.75 ; \mathrm{SD}=0.44$; score from 1 to 5 in the Experimental group) They also found that AR was easier and more comfortable to comprehend than was traditional 2-D drawing (average level of agreement $=4.8 ; \mathrm{SD}=0.52$; score from 1 to 5). Participants in the experimental group showed a great interest in using our AR training system for training (average level of agreement $=4.35 ; \mathrm{SD}=0.48 ;$ score from 1 to 5) and a naturally adaptive behavior response after the intervention. As a result, the AR training system helped them imagine and infer the 3D object status. By contrast, in hand-made materials, with regards to the performance in materials application in the preliminary phase, in fabrication of carpentry work, the scores of correct completion rate are no significant difference $(p>0.05)$ from the control group (both groups' completion rate were at the high level; Experimental: mean $=84.72 \%$; Controls: mean $=77.77 \%$ ) The main reason is that hidden mortice joint face is not a lot. Without using training of AR in control group, one is still allowed to fulfill the work in carpentry unit in a given time correctly. In mid-level carpentry unit, with a significant difference ( $\mathrm{p}<$ 0.05 ) in scores of fabrication of carpentry work (Experimental: mean $=80.55 \%$; Controls: mean $=68.05 \%$ ), the experimental group has exceeded both in level of mortice-tenon completion 
and completion rate. The result has demonstrated that the experiment group acquired an inherent spatial structure concept on geometry surface and outperformed the control group due to the undertaking of the AR training. And in complicated advanced carpentry unit, the difference between experimental and control group is more salient $(\mathrm{p}<0.05)$ $($ Experimental: mean $=75 \%$; Controls: mean $=58.33 \%)$. Most students in experimental group are able to complete the fabrication and assembling of chair forming parts; however, in control group nearly one third of the students failed the fabrication, or in need of teaching unit of a longer time for completion. So the benefit of AR technology in spatial structure training is apparent.

\section{CONCLUSIONS}

From the questionnaire and instructor's evaluation, we find that AR technology truly is conducive to judging of mortice-tenon structure in space. And through overlapping of information of AR technology, students are able to determine the spatial position of subjects, understanding from it some implicit view problems, having an obvious improvement in abilities compared with students in control group. There are some characteristics of AR that contribute in the training, including interaction training platform of AR technology integrated with hand operation which increases cognitions correlation and understanding for hand operation and spatial shapes; (2) recognition drawing in each side views of controller cast into 3D subject of space helping students to understand view judgements; (3) 3D motion picture by overlapping of AR, switching of rendering image and perspective, helpful for beginners to learn the spatial status; (4) presentation of $3 \mathrm{D}$ subject is conducive to learning of mortice-tenon, semi-transparent visual information overlapped onto controlling subject lowers judgement obstacles in spatial awareness for beginners. As a whole, this research takes the stand that AR efficiently strengthens students' recognition in spatial structure and views beginners and mainly enhances beginners' grasp of furniture carpentry skills.

\section{ACKNOWLEDGMENT}

We are grateful to the Executive Yuan and Ministry of Science and Technology for funding under project No. MOST 107-2218-E-027-013-MY2.

\section{REFERENCES}

[1] G. Roza, A Career as a Carpenter, The Rosen Publishing Group, 2010

[2] S. Cuendet, J. Dehler-Zufferey, C. Arn, E. Bumbacher, and P. Dillenbourg, "A study of carpenter apprentices' spatial skills," Empirical Research in Vocational Education and Training, vol. 6, no. 1, p. 3, 2014.

[3] K. A. Samsudin, A. Rafi, and A. S. Hanif, "Training in mental rotation and spatial visualization and its impact on orthographic drawing performance," Educational Technology \& Society, vol. 14, no. 1, pp. 179-186, 2011

[4] T. Huk, "Who benefits from learning with 3D models? The case of spatial ability," Journal of Computer Assisted Learning, vol. 22, no. 6, pp. 392-404, 2006.

[5] A. R. Arslan and S. S. Dazkir, "Technical drafting and mental visualization in interior architecture education," International Journal for the Scholarship of Teaching and Learning, vol. 11, no. 2, p. 15, 2017.

[6] M. Kavakli and J. S. Gero, "Sketching as mental imagery processing," Design Studies, vol. 22, no. 4, pp. 347-364, 2001.

[7] P. H. Maier, Raumliches Vorstellungsvermogenn, Peter Lang Frankfurt, Frankfurt, 1994.

[8] D. H. Uttal, N. G. Meadow, E. Tipton, L. L. Hand, A. R. Alden, C. Warren, and N. S. Newcombe, "The malleability of spatial skills: A meta-analysis of training studies," Psychological Bulletin, vol. 139, no. 2, p. 352, 2013.

[9] F. Helmi and K. A. M. Khaidzir, "Evaluating the impact of novice students "sketches on their mental imagery," International Journal of Scientific and Technology Research, vol. 5, no. 2, pp. 15-17, 2016.

[10] E. S. Yagmur-Kilimci, "3D mental visualization in architectural design,” Doctoral dissertation, Georgia Institute of Technology, 2010.

[11] H. Ishii and B. Ullmer, "Tangible bits: Towards seamless interfaces between people, bits and atoms," In: CHI '97, ACM, New York, NY, USA, pp. 234-241, 1997

[12] A. Manches and C. O’Malley, "Tangibles for learning: a representational analysis of physical manipulation," Personal and Ubiquitous Computing, vol. 16, no. 4, pp. 405-419, 2012.

[13] S. Do-Lenh, P. Jermann, S. Cuendet, G. Zufferey, and P. Dillenbourg, "Task performance vs. learning outcomes: A study of a tangible user interface in the classroom," in Proc. European Conference on Technology Enhanced Learning, pp. 78-92, Springer, Berlin, Heidelberg, September 2010.

[14] Z. Y. Hoe, I. J. Lee, C. H. Chen, and K. P. Chang, "Using an augmented reality-based training system to promote spatial visualization ability for the elderly," Universal Access in the Information Society, pp. 1-16, 2017.

[15] H. C. K. Lin, M. C. Chen, and C. K. Chang, "Assessing the effectiveness of learning solid geometry by using an augmented reality-assisted learning system," Interactive Learning Environments, vol. 23, no. 6, pp. 799-810, 2015.

[16] J. C. Yang, C. H. Chen, and M. C. Jeng, "Integrating video-capture virtual reality technology into a physically interactive learning environment for English learning," Computers \& Education, vol. 55, no. 3, pp. 1346-1356, 2010.

[17] A. K. Erbas and A. A. Yenmez, "The effect of inquiry-based explorations in a dynamic geometry environment on sixth grade students' achievements in polygons," Computers \& Education, vol. 57, pp. 2462-2475, 2011.

[18] Silva and Silveira, presented ARGeometric, an educational tool in the field of geometry which proposes a game development methodology, 2012.

[19] D. Rohendi, S. Septian, and H. Sutarno, "The use of geometry learning media based on augmented reality for junior high school students," IOP Conference Series: Materials Science and Engineering, vol. 306, no. 1, p. 012029, IOP Publishing, February 2018.

[20] K. H. Cheng and C. C. Tsai, "Affordances of augmented reality in science learning: Suggestions for future research," Journal of Science Education and Technology, vol. 22, no. 4, pp. 449-462, 2013.

[21] G. Wiedenbauer and P. Jansen-Osmann, "Manual training of mental rotation in children," Learning and Instruction, vol. 18, no. 1, pp. 30-41, 2008.

[22] R. Wright, W. L. Thompson, G. Ganis, N. S. Newcombe, and S. M. Kosslyn, "Training generalized spatial skills," Psychonomic Bulletin \& Review, vol. 15, no. 4, pp. 763-771, 2008.

[23] G. J. Hwang and H. F. Chang, "A formative assessment-based mobile learning approach to improving the learning attitudes and achievements of students," Computers \& Education, vol. 56, no. 4, pp. 1023-1031, 2011.

[24] B. E. Shelton and N. R. Hedley, "Exploring a cognitive basis for learning spatial relationships with augmented reality," Technology, Instruction, Cognition and Learning, vol. 1, no. 4, p. 323, 2004.

[25] M. Hegarty, S. Mayer, S. Kriz, and M. Keehner, "The role of gestures in mental animation," Spatial Cognition and Computation, vol. 5, no. 4, pp. 333-356, 2005.

[26] R. L. Klatzky, B. Wu, D. Shelton, and G. Stetten, "Effectiveness of augmented-reality visualization versus cognitive mediation for learning actions in near space," ACM Transactions on Applied Perception (TAP), vol. 5, no. 1, p. 1, 2008.

[27] H. Kaufmann and D. Schmalstieg, "Mathematics and geometry education with collaborative augmented reality," Computers \& Graphics, vol. 27, no. 3, pp. 339-345, 2003.

[28] J. Martín-Gutiérrez, J. L. Saorín, M. Contero, M. Alcañiz, D. C. Pérez-López, and M. Ortega, "Design and validation of an augmented 
book for spatial abilities development in engineering students," Computers \& Graphics, vol. 34, no. 1, pp. 77-91, 2010.

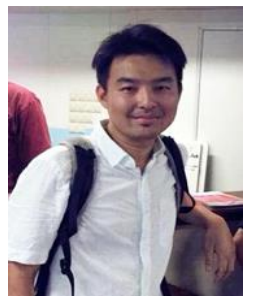

I-Jui Lee is assistant professor in the Department of Industrial Design, Taipei University of Science and Technology and chairs of the Ergonomic and Interaction Design Lab. His research interests are in the areas of Augmented Reality (AR), interaction design, tangible user interfaces (TUI), human-computer interaction, computer-supported collaboration and design for children. A central theme of his research is exploring design spaces of novel interactive technologies that support people's needs by expanding ways they perceive, interpret and interact with the physical world.

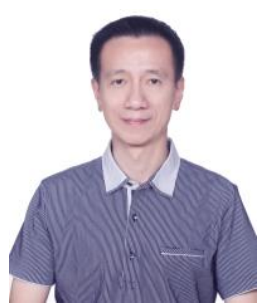

Ting-Chun Hsu is Ph.D. student in the doctoral program in design, College of Design of Nationa Taipei University of Technology. His main research interests are woodwork heritage, interior design, and furniture design.

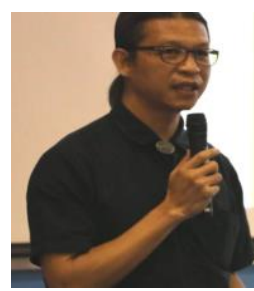

Ten-Li Chen is professor in the Department of Industrial Design, Taipei University of Science and Technology. His main research interests are woodwork heritage, interior design, culture design and furniture design.

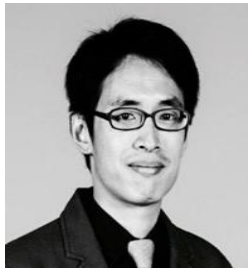

Meng-Cong Zheng is associate PROFESSOR in the Department of Industrial Design, Taipe University of Science and Technology, and chairs the Design Psychology Laboratory. Also, as a member of design competitions, design journals, and government subsidy schemes program review committee. Research expertise is universal design, design psychology and usability evaluation. My lab team has been working with the enterprise on some product design projects for a long time. The content of the projects extends from the hardware appearance design to the UI/UX design of the user's internal experience. The project results also won many awards in design competitions. We hope to explore the relationship between users, products, and environment, and provide a complete design solution for various industries. 